THEORY AND METHODS

\title{
Population health. More than the sum of the parts?
}

\author{
Daniel D Reidpath
}

J Epidemiol Community Health 2005;59:877-880. doi: 10.1136/jech.2005.036046

The past decade has seen an upsurge of interest in the development of summary measures of population health. Almost invariably the measures have relied on "rolling up" individual level health data such as mortality data or life expectancy data. The approach, however, of treating population health as a synthesis of aggregated individual level data is a historical and statistical convenience.

Although there has been some debate in the literature about whether one should also examine the equity of the distribution of health, the general practice has been to treat the level of a population's health and the distribution of health within a population as separate issues. Without recourse to contentious notions of equity, this paper examines the possibility of treating populations as more than simply the sum of their parts by combining individual level health data with population level data about the distribution of health. This approach may provide policy makers with additional ways of thinking about what it means to improve a population's health.

"...there is no such thing as society. There are [just] individual men and women..." (Margaret Thatcher, Women's Own Magazine, 3 Oct 1987).

Correspondence to: Professor D D Reidpath, School of Health Sciences and Social Care, Brunel University, West London, Uxbridge, Middlesex UB8 3PH, UK; daniel.reidpath@ brunel.ac.uk

Accepted for publication 6 May 2005 instance, the wealth of nations used to be evaluated for countries, not for aggregations of the individuals within those countries. ${ }^{7}$ Adam Smith, the 18th century author of An Inquiry into the Nature and Causes of the Wealth of Nations, for instance, "...seems to have felt that there was something novel in his plan of treating the condition of the people [rather than the country] as the important thing" (page 225). ${ }^{7}$

What was novel for Adam Smith has since become the norm. Wealth is now often measured as a function of aggregated individual level data. It is the cornerstone of current utility maximisation strategies to improve population wellbeing by achieving the greatest good for the greatest number. ${ }^{8}$ Indeed, Bentham argued specifically that,

"...The community is a fictitious body, composed of the individual persons who are considered as constituting as it were its members. The interest of the community then is, what? - the sum of the interests of the several members who compose it." (page $126)^{8}$

In economics, however, particularly in the field of development economics, there is an alternative view, that it is insufficient to measure a population's wellbeing solely on the basis of aggregated individual wellbeing. A measure of population wellbeing must also take account of the distribution of wellbeing within the population. ${ }^{9}{ }^{10}$ Neither is it enough to examine these issues separately; rather, the wellbeing of a population is inextricably linked with both the distribution of wellbeing and the average of individual wellbeing.

If economists are questioning the separability of the distribution of wealth/wellbeing within a population from the measurement of population wealth/wellbeing, should health metricians not be similarly concerned? The analogous debate, however, has not occurred in any meaningful way. Typically the possibility is mooted and dismissed en passant. ${ }^{11}$ Although the distribution of health in a population has been of interest to researchers, this has almost always been grounded in a broader concern with matters of social equity, ${ }^{12}$ which is reflected in a separate and distinct literature on the measurement of health inequality. ${ }^{13}{ }^{14}$ Indeed, it has been argued that the distribution of health should be treated separately from the level of a population's health because "...it is simpler, closer to the tradition of health statistics and more easily communicated to the general public to have separate summary measures of average population health and health inequality" (page 752). ${ }^{11}$ Wolfson described this as the necessary differentiation 
between the size of the pie and the manner in which the pie is divided (page 175). ${ }^{15}$

Nord, ${ }^{16}$ and Pinto-Prades and Abellan-Perpinan ${ }^{17}$ are counter examples to this trend, and have touched on the legitimacy of the separation-but tangentially. They considered people's preferences for two populations with different mixes of health states. The approach they used (the "veil of ignorance", which is discussed more fully later) permits inferences to be drawn about which of two populations is the healthier. ${ }^{1618}$ Unfortunately, the populations that were contrasted have unknown individual levels of average health. Although a preference can be elicited for one population over another, the effect of the average level of individual health in the population and the effect of the distribution of health cannot be disentangled. The relation between the distribution of health and the nature of population health was further obscured by the focus on specific disease states, which confounded the generality of the argument to large populations with realistically diverse health states.

The issue of whether a population's health is best summarised by some function of aggregated individual health is not an idle one. It is well known that measures of population health drive policy and incorrect measures drive policy in the wrong direction. ${ }^{19}$ This has billion dollar implications for funding, and can radically change health agendas. If one "settles" for a particular form of measure, without due consideration given to alternatives, one also settles for particular forms of funding regimen, policy, and intervention.

It is argued here that a statistic based on aggregated individual level health data is, plausibly, an insufficient summary measure of population health. Moreover, the shape of the distribution of health can carry critical information about the health of the population that is not captured by aggregated individual level data.

The remainder of this paper is devoted to the proposition that if one is to derive a single summary statistic of the health of a population, then in the construction of that statistic, one cannot ignore the distribution of health within the population. To examine the proposition, the following steps are made.

1. Populations can be constructed that are equal with respect to their average aggregated individual level health, but unequal with respect to the distribution of individual health.

2. People have a preference for a life in one population over life in another, when ceteris paribus, the difference is the distribution of health in the populations.

3. People will trade off one population's average level of individual health to achieve equality in their preference for the two populations.

These are now expanded upon.

\section{THE CONSTRUCTION OF TWO POPULATIONS}

Figure 1 shows two separate population distributions of life expectancy. The specifics of the figure are for illustrative purposes, and do not affect the generality of the argument (which neither relies on the choice of population health measure (life expectancy) nor the choice of distribution (Gaussian)). The critical feature is that both populations have the same average "rolled up" individual level health characteristic (in this example a life expectancy of 50 years), but the shape of the distributions of health for the populations are different.

Population 2 has greater variation in life expectancy than population 1. According to current population health metrics, the health of population 1 and population 2 should be judged

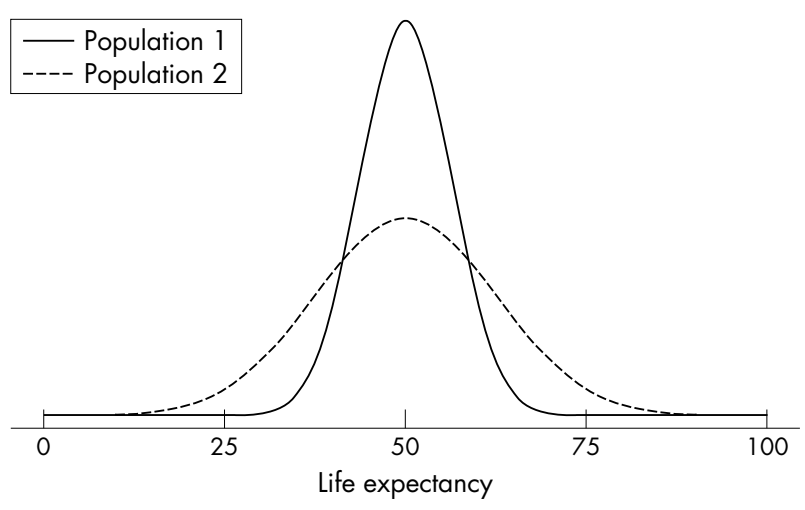

Figure 1 Two populations with equal average health and unequal distribution of health.

to be identical because their average health is the same. ${ }^{11}$ It should, however, also be observed that people in population 1 can have little expectation of surviving past their mid-60s. Similarly, they can have little expectation of a death before their late 20s. In contrast, members of population 2 will have an increased risk of a foreshortened life and a greater chance of experiencing their biblical entitlement of three score years and ten.

Someone with an equity focus may have a preference for one population over the other (quite possibly preferring population 1 over population 2). This preference would be an expression of a normative view about how health ought to be distributed in a fair society. Assume, however, that the only difference between these two populations is a randomly determined and completely uninfluenceable length of life patterned by the mean and standard deviation of the life expectancy of each population. In the absence of any sociostructural determinants, the shape of the distribution is not a matter of equity. In contrasting the two populations attention can (by construction) be restricted to a consideration of the average life expectancy and the distribution of life expectancy.

It clearly is not the case that health is randomly distributed. Health is influenced by a host of individual, social, and environmental factors. However, in the momentary suspension of disbelief, one has an opportunity to explore the notion that the shape of the distribution of health carries information about the health of a population beyond the average health of the individuals in the population. Furthermore, one can do this unencumbered by competing arguments associated with notions of equity, and how these should be managed in the measurement of population health.

\section{A PREFERENCE FOR ONE POPULATION}

A person coming from either of the two populations cannot choose how long their life will be. Furthermore, their statistical expectancy about the length of their life will be the same without regard to the population into which they are born. If a person, however, could choose to be born into one or other of the two populations, which population would be preferred?

In answering this, the "veil of ignorance" borrowed from the wardrobes Harsanyi ${ }^{20}$ and Rawls ${ }^{21}$ provides a useful device. The "veil of ignorance" is a means of posing a thought experiment in such a way that the ponderer is ignorant of how the outcome of their choice will advantage or disadvantage them individually. A number of researchers have suggested its use in the evaluation of population health. ${ }^{16-18}$ In the variation adopted here, the ponderer is ignorant of how their specific life will evolve and end, but 
they are aware that the length of any individual life is a random function of the mean and standard deviation of the population's distribution.

If a person is indifferent between life in either population, then the argument stops. It may be concluded, at least in this regard, that preference is not influenced by the variation in the distribution of health and may simply be a function of the "rolled up" individual level data expressed in a single summary statistic-life expectancy. This would support the current view of population health and how it should be measured.

On the other hand if a person does not have a sense of equipoise and can state a preference for one population over the other, then that preference must be a function, not of the average of the aggregated individual level health data, but of a health characteristic that can only be expressed at the population level-the shape of the distribution of individual health. Prima facie, it would then seem that the health of populations could not be assessed solely on the basis of aggregated individual level data. Rather, there is information relevant to the health of a population that can only be derived from the gestalt that cannot be ascertained from the sum of its parts.

This argument is not dissimilar to the arguments behind such notions as the quality adjusted life year (QALY). Given two lives that are identical in all but one respect, which life is preferred? The remainder of one life is lived in full health, the remainder of the other is lived with a serious and debilitating disease. The expressed preference for $x$ additional years of life in full health rather than $y$ additional years of life with a debilitating disease is not simply a demonstration of an interesting social preference. The preference is itself an expression of a fundamental view about the nature of health. Health is about quality of the state, not just quantity of it.

The corollary has been has been proposed about the health of populations:

\section{...population A is healthier than population B if, and only if, an individual behind a veil of ignorance would prefer to be one of the existing individuals in population $A$ rather than an existing individual in population B, holding all nonhealth characteristics of the two populations to be the same. (page 986$)^{18}$}

The expected length of a life of a population (even if the individual lives are adjusted for quality prior to aggregation) may not be sufficient, if the distribution of health in the population affects the quality of population health. Any

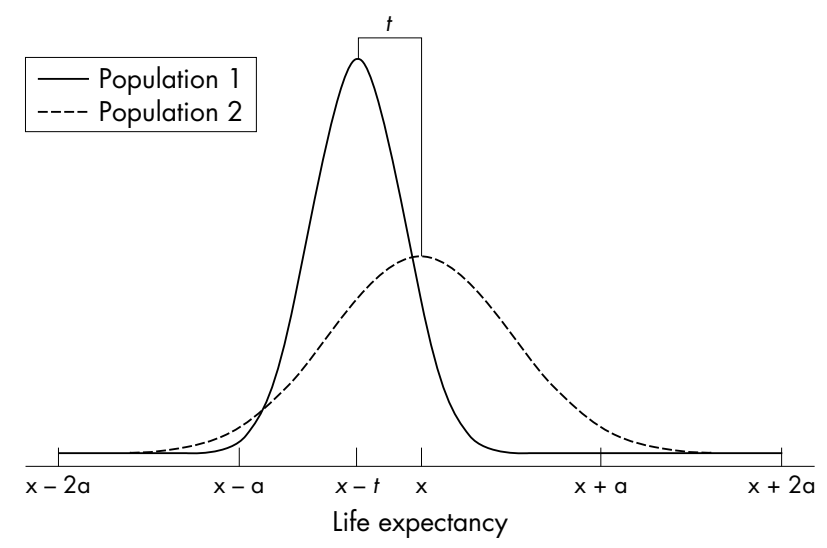

Figure 2 The point at which two populations of unequal average health are equally healthy. expression of preference for one population over another cannot be mistaken for an expression of a view about equity, because, by design in this exercise length of life is randomly determined, neither fair nor unfair-it just is. The preferred population is necessarily the healthier population. ${ }^{18}$

This now leaves open a question about an appropriate metric for expressing the health of a population when individual and population level health characteristics are included.

\section{THE TRADE OFF}

The strength of the argument for QALYs gained intuitive appeal in the time trade off exercise, because the metric for expressing health (length of life) can be traded off against the quality of the life. ${ }^{22}$ Thus using the fixed metric of years of life, one can see that people are prepared to exchange a foreshortened life in full health for a full life in less than full health.

This approach can be extended to populations (although alternative approaches could apply equally well). ${ }^{23}$ If a person prefers one population to the other, how many years of expected life would they be prepared to trade, before their preference would reverse? In other words, if the preferred population distribution could be shifted to the left (reducing mean life expectancy but maintaining the shape of the distribution), how far to the left could it be moved before the person expressed indifference between living a life in one population or the other?

At some point a person will be indifferent. The point of indifference may occur after shifting the initially preferred population to the left (that is, reducing average life expectancy) by one hour, one year, or 10 years (fig 2 ).

As the person shifts population 1 to the left, reducing its average life expectancy, something quite profound occurs. Population 2, with health $x$ (as measured here by the mean life expectancy), is still judged to be no better than population 1 , even though population 1 has a reduced average life expectancy of $x-t$, where $t$ is the years of life lost attributable to the trade off.

Holding the idea of the trade off in mind-not the specifics of the trade off presented here, but the general possibility of conducting such a trade off-is one of the populations healthier than the other? If the results of the trade off point to an indifference between one population with mean life expectancy $x$ and the other population with mean life expectancy $x-t,(t>0)$, then there seems to be a powerful argument to suggest that the populations in figure 1 could not be considered equally healthy. ${ }^{18}$ Similarly if there were indifference between the two populations in figure 2, when one population has a lesser average life expectancy, then that is the point at which they would appear to be equally healthy.

\section{IMPLICATIONS}

The argument presented here evolves naturally from the earlier work of others. ${ }^{16-18}$ It is, none the less, challenging because it suggests that, in contrast with generally received wisdom, ${ }^{11}$ in measuring population health it may be

\section{What this paper adds}

This paper re-examines the question of whether "population health" is more than the aggregate health of the individuals in a population. Unlike earlier literature that has tried to do this, it does so without having to argue that a fair society is healthier (rather than just nicer) than an unfair society. This equity question has been a stumbling block in the analysis of whether populations are simply clusters of individuals. 


\section{Policy implications}

If populations can become units of interest in and of themselves, separate from the individual, then interventions can be targeted at characteristics of populations. This has profound implications for what public health can do, and for the allocation of health resources.

necessary to consider factors that cannot simply be derived from individual level data. It forces us as metricians and public health specialists to confront the values that we often unthinkingly entrench within our measures, because these influence our funding, our interventions, and our policies. ${ }^{19}$

Were Thatcher and Bentham right? Are populations simply aggregations of individuals - or are there qualities about a population as a whole that transcend the parts? If there are, and we want to improve the health of populations, then we need to measure those things, understand how to integrate those data with aggregated individual level data, and use that synthesis to inform policy development. If one collects the information, one can also make an informed choice about when to use it and when not to use it.

Expressing population health as a synthesis of aggregated individual level data has been a historical and statistical convenience. Values are so deeply embedded in the entire project of measuring population health and this approach is simply one of the means to examine whether the shape of the distribution of health also carries important information about the health of the population itself.

This paper relies on the conceit that individual health status is randomly determined and uninfluenceable. That world, of course, does not exist. Wealth, sex, race, environment, behaviour, culture, etc, all influence health outcomes. When it has been argued, however, that the shape of the distribution is important in the measurement of population health, the metricians' counter argument has been that the shape of the distribution is a matter of equity not health. ${ }^{11}{ }^{15}$ The argument here essentially avoids that debate stopper. Even when equity is excluded from the argument, the shape of the distribution remains as an issue relevant to the measurement of population health. It seems that the health of a population is greater than the sum of its parts.

\section{ACKNOWLEDGEMENTS}

I would like to thank Erik Nord, Jeff Richardson and Pascale Allotey for commenting on earlier drafts of this paper. Rebecca Marsh provided a sounding board for many of the ideas. The comments of three anonymous reviewers helped to improve the paper.

Funding: the work was supported in part by a Senior Research Fellowship from the Victorian Health Promotion Foundation.
Competing interests: none declared.

\section{REFERENCES}

1 Wolfson MC. On the uses of summary measures of population health. In: Murray CJL, Salomon JA, Mathers C, et al. Summary measures of population health: concepts, ethics, measurement and applications. Geneva: World Health Organisation, 2002:61-6.

2 Young TK. Population health: concepts and methods. 2nd ed. New York: Oxford University Press, 2004

3 World Health Organisation. The world health report 2000: health systems: improving performance. Geneva: World Health Organisation, 2000.

4 Mathers C, Vos T, Stevenson C. The burden of disease and injury in Australia. Canberra: Australian Institute of Health and Welfare, 1999.

5 Blaxter M. The health of children: a review of research on the place of health in cycles of disadvantage. London: Heinemann Educational Books, 1981

6 Reidpath DD, Allotey P. Infant mortality rate as an indicator of population health. J Epidemiol Community Health 2003;57:344-6.

7 Cannan E. Wealth: a brief explanation of the causes of economic welfare. London: King, 1914.

8 Bentham J. A fragment on government and an introduction to the principles of morals and legislation. Oxford: Basil Blackwell, 1967.

9 Drèze J, Sen A. India: development and participation. New Delhi: Oxford University Press, 2002.

10 Sen A. Development as freedom. New York: Alfred A Knopf, 1999.

11 Murray CJL, Salomon JA, Mathers C, et al. Summary measures of population health: conclusions and recommendations. In: Summary measures of population health: concepts, ethics, measurement and applications. Geneva: World Health Organisation, 2002:731-56.

12 Evans T, Whitehead M, Diderichsen $F$, et al, eds. Challenging inequities in health: from ethics to action. New York: Oxford University Press, 2001.

13 Gakidou EE, Murray CJ, Frenk J. Defining and measuring health inequality: an approach based on the distribution of health expectancy. Bull World Health Organ 2000;78:42-54.

14 Anand S, Diderichsen F, Evans T, et al. Measuring disparities in health: methods and indicators. In: Evans T, Whitehead M, Diderichsen F, et al, eds. Challenging inequities in health: from ethics to action. New York: Oxford University Press, 2001:48-67.

15 Wolfson MC. Levels of health and inequality in health. In: Murray CJL, Salomon JA, Mathers C, et al, eds. Summary measures of population health: concepts, ethics, measurement and applications. Geneva: World Health Organisation, 2002:171-5.

16 Nord E. My goodness - and yours: a history, and some possible futures, of DALY meanings and valuation procedures. In: Murray CJL, Salomon JA, Mathers C, et al, eds. Summary measures of population health: concepts, ethics, measurement and applications. Geneva: World Health Organisation, 2002:139-46.

17 Pinto-Prades JL, Abellan-Perpinan JM. Measuring the health of populations: the veil of ignorance approach. Health Econ 2005;14:69-82.

18 Murray CJL, Salomon JA, Mathers C. A critical examination of summary measures of population health. Bull World Health Organ 2000;78:981-94.

19 Murray CJL. Rethinking DALYs. In: Murray CJL, Lopez AD, eds. The global burden of disease: a comprehensive assessment of mortality and disability from diseases, injuries, and risk factors in 1990 and projected to 2020. Cambridge, MA: Harvard School of Public Health, 1996:1-98.

20 Harsanyi J. Cardinal utility in welfare economics and in the theory of risk taking. Journal of Political Economy 1953;61:434-5.

21 Rawls J. A theory of justice. Cambridge: Harvard University Press, 1971.

22 Stiggelbout AM, Kiebert GM, Kievit J, et al. Utility assessment in cancer patients: adjustment of time tradeoff scores for the utility of life years and comparison with standard gamble scores. Med Decis Making 1994; 14:82-90.

23 Richardson J. Evaluating summary measures of population health. In: Murray CJL, Salomon JA, Mathers C, et al. Summary measures of population health: concepts, ethics, measurement and applications. Geneva: World Health Organisation, 2002:147-59. 